\title{
Analysis of interface states of the pentacene organic thin-film phototransistor by conductance technique
}

\author{
S. Okur ${ }^{\mathrm{a}}$, F. Yakuphanoglu ${ }^{\mathrm{b}, *}$ \\ a Department of Physics, Faculty of Science, Izmir Institute of Technology, Gülbahçe, Campus, Urla, Izmir 35430, Turkey \\ ${ }^{\mathrm{b}}$ Firat University, Faculty of Arts and Sciences, Department of Physics, Elazığ, Turkey
}

\section{A R T I C L E I N F O}

\section{Article history:}

Received 23 August 2008

Received in revised form 15 October 2008

Accepted 19 November 2008

Available online 6 December 2008

\section{Keywords:}

Organic semiconductor

Thin-film transistor

Interface state density

\begin{abstract}
A B S T R A C T
A pentacene thin-film transistor with a channel width of $300 \mu \mathrm{m}$ and a channel length of $30 \mu \mathrm{m}$ has been successfully fabricated on n-Si substrate with thermally oxidized $\mathrm{SiO}_{2}$ as a gate insulator. The photovoltaic and interface state density properties of the transistor have been investigated. A pentacene film of $200 \mathrm{~nm}$ thickness was deposited on the $\mathrm{SiO}_{2}$ layer with a vacuum thermal evaporator. Atomic force microscopy images of the pentacene film on $\mathrm{SiO}_{2}$ insulating layer show a homogeneous film surface with the rms roughness of $11 \mathrm{~nm}$. The transistor shows p-channel characteristics, as a result of positive carriers generated in the pentacene film for the negative bias voltages applied to the gate.

The photosensitivity $\left(I_{\mathrm{ph}} / I_{\mathrm{dark}}\right)$ is measured as 1.45 at an illumination intensity of 3500 lux at the off state. This suggests that the pentacene thin-film transistor shows a phototransistor characteristic. The field-effect mobility of the pentacene OTFT was found to be $0.021 \mathrm{~cm}^{2} /(\mathrm{Vs})$. The interface state density of the transistor was determined using conductance technique and was found to be about $1.191 \times 10^{10} \mathrm{eV}^{-1} \mathrm{~cm}^{-2}$.
\end{abstract}

(C) 2008 Elsevier B.V. All rights reserved.

\section{Introduction}

Organic thin-film transistors (OTFTs) have been extensively investigated in recent years and steady progress in performance of these devices has been realized [1-7]. OTFT devices have been used in low-cost, large-area, flexible electronic applications such as allpolymer integrated circuits [8,9], polymer-dispersed active-matrix displays [10-12], large-area sensor arrays [13,14], biochemical sensors [15] and radio frequency identification tags [16]. The active layer of an OTFT is usually made of a thin film of highly conjugated n-channel $[17,18]$ or p-channel [19-21] small molecules, such as perfluorinated copper-phthalocyanine (F16-CuPc) [22] or pentacene $[23,24]$. Among these organic molecules, pentacene $\left(\mathrm{C}_{22} \mathrm{H}_{14}\right)$ has the highest carrier mobility (more than $5 \mathrm{~cm}^{2} /(\mathrm{Vs})$ ) and on/off ratio $[25,26]$ when used a semiconducting transport layer for OTFTs [27-29] and optoelectronic devices [30-32], making it one of the most promising organic semiconductors. Pentacene consists of stacked molecular layers arranged in a herringbone structure with interplanar spacing $d_{001}=14.1 \AA$ [33]. Van der Waals forces are effective between its molecular layers [34,35]. Several techniques, such as photoelectron emission microscopy (PES) [36], potential imaging mapping [37], and scanning Kelvin probe microscopy

\footnotetext{
* Corresponding author. Tel.: +90 424 2370000x6591; fax: +90 4242330062.

E-mail address: fyhan@hotmail.com (F. Yakuphanoglu).
}

(SKPM) $[38,39]$ have been used to probe local defects originating from structural disorders, crystalline domain size, shape, and height of the pentacene layer itself. Metastable defects under bias voltage using space-charge limited current spectroscopy [40], deep charge traps using electric force microscopy [41] and shallow traps by using scanning tunneling microscopy (STM) [33] have been observed to clarify the charge transport mechanism at the interface between pentacene and insulating dielectric layers on various substrates [42]. The field-effect mobility and performance of an OTFT device depend also on deposition rate and substrate temperature that affect the morphology and molecular ordering of semi-crystalline organic semiconductors like pentacene $[43,44]$.

Optical response of pentacene in the UV and visible regions is promising for use in phototransistor applications $[45,46]$. Combination of light detection and signal amplification in a single device without noise problems [47-49] gives superior performance to pentacene-based OTFTs for photo-sensor applications [50,51].

In this work, we have prepared a pentacene thin-film transistor with top contact geometry as an optical sensor to investigate the photo-sensing characteristics of the device under the illumination of visible light. Furthermore, our aim is to show whether the interface states that are formed during the fabrication of the pentacene thin-film transistor are effective on the device characteristics. To this end, we have characterized the interface states using the conductance-frequency method. 


\section{Experimental}

A top contact thin-film transistor (OTFT) has been fabricated with a p-channel organic semiconductor pentacene with $98 \%$ purity, purchased from Sigma-Aldrich. An n-type (N/Phos) single crystal silicon wafer pre-polished on one side and having a $\langle 100\rangle$ surface orientation, thickness of $530 \mathrm{~mm}$, diameter of $100 \mathrm{~mm}$ and $2.00 \Omega-\mathrm{cm}$ resistivity was purchased from Si-Mat Silicon Wafers Company, and used as a substrate. A $250 \mathrm{~nm}$ thick $\mathrm{SiO}_{2}$ layer was thermally grown by annealing of an n-type Si wafer substrate for $1 \mathrm{~h}$ at $1250^{\circ} \mathrm{C}$ in a pure oxygen atmosphere and used as a gate dielectric layer of the OTFT device. A $200 \mathrm{~nm}$ thick pentacene film was deposited on the $\mathrm{SiO}_{2}$ layer with a vacuum evaporator and was used as the active layer of the organic thin-film transistor. A gold metal thin film (purity 99.95\%) with a thickness of $200 \mathrm{~nm}$ was thermally evaporated from a tungsten filament under $6 \times 10^{-6}$ Torr vacuum. Gold top contacts on the $\mathrm{n}-\mathrm{Si} / \mathrm{SiO}_{2} /$ pentacene structure were formed having a channel length of $30 \mu \mathrm{m}$ and channel width of $300 \mu \mathrm{m}$ using a shadow mask. Fig. 1 shows the schematic diagram and optical microscopy images of the OTFT structure used in this work. The current-voltage characteristics $\left(I_{\mathrm{ds}}-V_{\mathrm{ds}}\right.$ and $\left.I_{\mathrm{ds}}-V_{\mathrm{gs}}\right)$ of the OTFT were measured with a KEITHLEY 2400 Sourcemeter and a KEITHLEY 6517 Electrometer. The capacitance-frequency, capacitance-voltage and conductance-frequency characteristics of the pentacene OTFT transistor were measured at the gold contacts (area of $0.14625 \mathrm{~cm}^{2}$ ) using a HIOKI 3532 LCR meter (Bohemia, USA). Photovoltaic measurements were employed using a $200 \mathrm{~W}$ halogen lamp. The morphology of the pentacene thin film as deposited on the $\mathrm{SiO}_{2}$ dielectric surface was examined with a Solver $\mathrm{P} 47 \mathrm{H}$

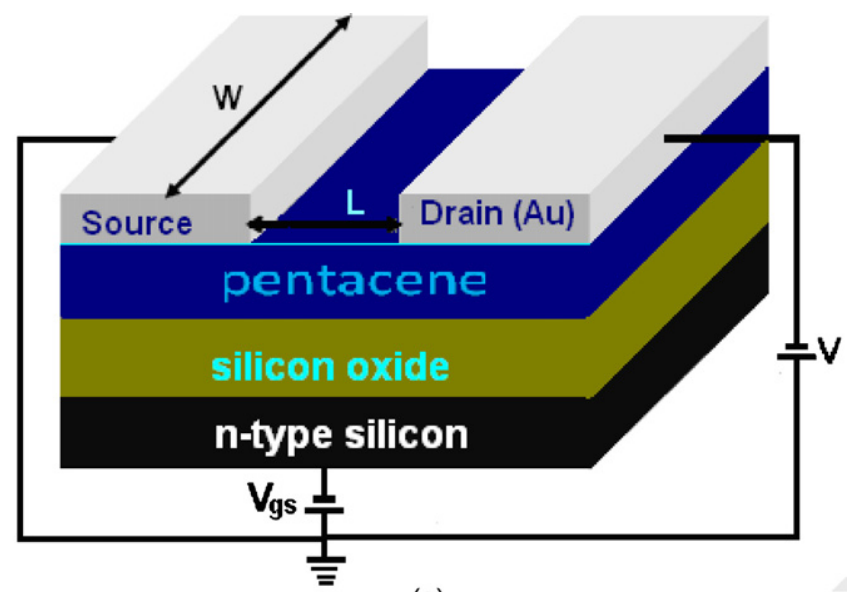

(a)

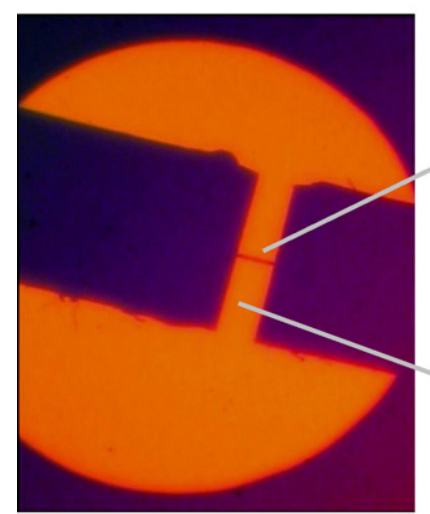

(b)

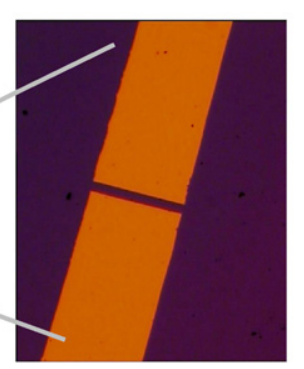

(c)
Fig. 1. (a) Schematic structure of OTFT; (b and c) optical microscopy images of n$\mathrm{Si} / \mathrm{SiO}_{2} /$ pentacene/Au OTFT device.

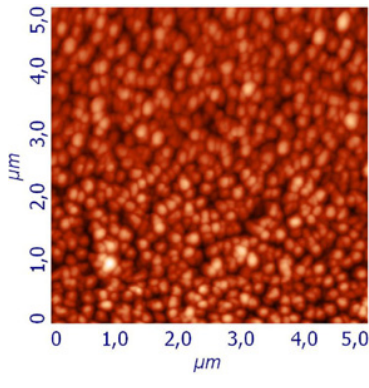

(a)

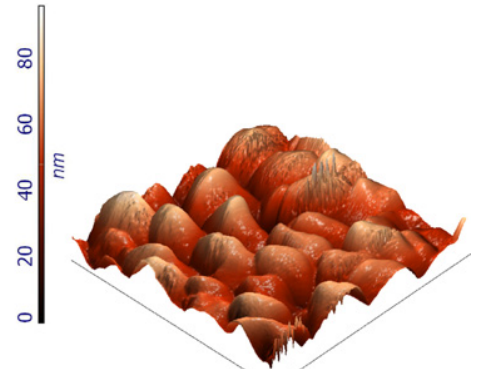

(b)
Fig. 2. Atomic force microscopy (AFM) images of pentacene film on $\mathrm{SiO}_{2}$ : (a) $2 \mathrm{D}$ image with $5 \mu \mathrm{m} \times 5 \mu \mathrm{m}$ scan size; (b) 3D image with $1 \mu \mathrm{m} \times 1 \mu \mathrm{m}$ scan size.

atomic force microscope (NT-MTD) (Moscow, Russia) operating in tapping mode in air at room temperature. Diamond-like carbon (DLC) coated NSG01_DLC silicon cantilevers (from NT-MTD) with a $2 \mathrm{~nm}$ tip apex curvature were used at its resonance frequency of $150 \mathrm{kHz}$. The Nova 914 software package was used to control the SPM system and for the analysis of the AFM images.

\section{Results and discussion}

\subsection{Output characteristics of the pentacene thin-film transistor}

The two-dimensional and three-dimensional atomic force microscopy (AFM) images of a pentacene film deposited on a $\mathrm{SiO}_{2}$ dielectric surface are shown in Fig. 2a and b, respectively. The AFM image shows a homogeneous pentacene film surface with the rootmean-square (rms) roughness of $11 \mathrm{~nm}$. As seen from Fig. 2(a), the pentacene grains on $\mathrm{SiO}_{2}$ form ellipsoidal particle shapes with aspect ratio of $150 \mathrm{~nm} / 200 \mathrm{~nm}$. The grain size may be attributed to the wetting properties of the dielectric layer. Pentacene films with larger grain sizes yield higher carrier mobilities [52,53].

Fig. 3 shows the drain current-voltage curves of the transistor under different gate voltages. As seen in Fig. 3, the OTFT device indicates a clear p-channel transistor behavior, since positive carriers are generated in the pentacene organic semiconductor layer upon application of negative gate voltages. The drain current $I_{\mathrm{d}}$ increases with $V_{\mathrm{ds}}$ and saturates at higher voltages when the gate voltage is varied between -15 and $15 \mathrm{~V}$. The drain current usually tends to saturate due to the pinch-off of the accumulation layer if the drain voltage $V_{\mathrm{ds}}$ is more negative than the applied gate voltage $V_{\mathrm{gs}}$. At

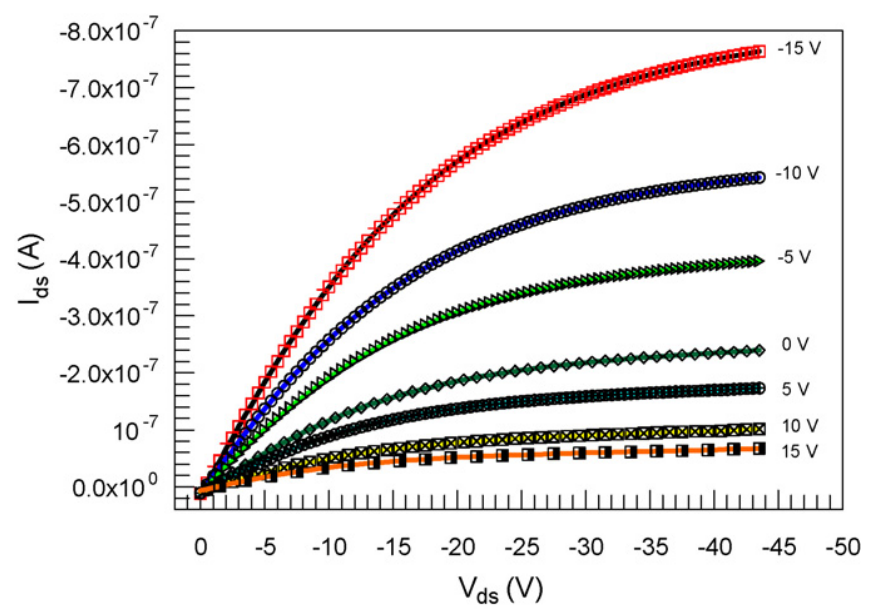

Fig. 3. Output characteristics of the pentacene thin-film transistor at different gate voltages. 


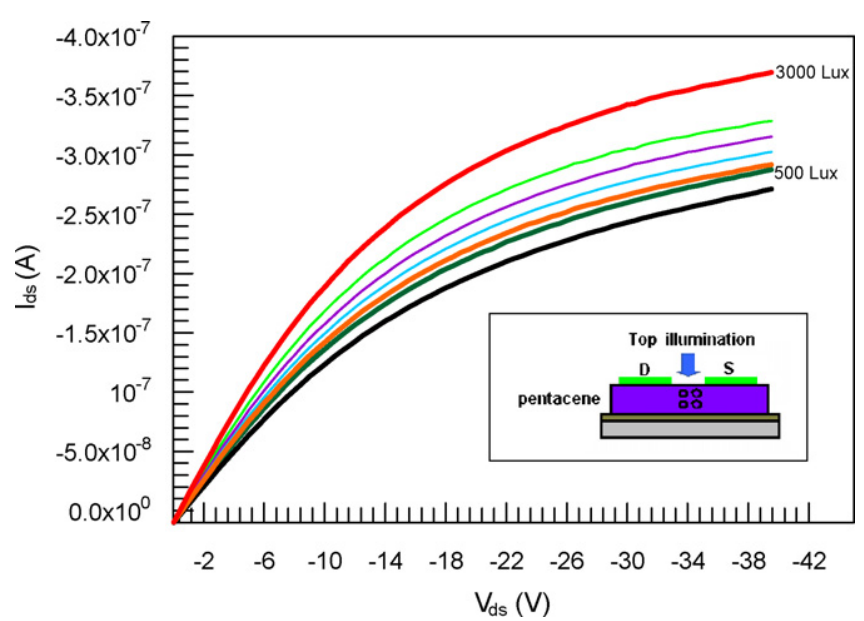

Fig. 4. Output characteristics of the pentacene thin-film transistor at various illumination intensities for $V_{g}=0 \mathrm{~V}$.

lower voltages, the drain current-voltage curves exhibit good linearity of response. This confirms that a good ohmic contact has been established between the pentacene and gold contacts.

Fig. 4 shows the drain-current curves of the pentacene thinfilm transistor under various illumination intensities from 500 to 3000 lux, using a tungsten filament white light source. Accordingly as seen in Fig. 4, the transistor is thus sensitive to illumination intensity in the visible white light range. This suggests that the pentacene thin-film transistor shows phototransistor characteristics. The drain current of the transistor increases with increasing illumination intensity. The photosensitivity $\left(I_{\mathrm{ph}} / I_{\mathrm{dark}}\right)$ was measured as 1.45 at an illumination intensity of 3500 lux under $V_{g}=0$. This value is low. Liu et al. [54] have found that the photosensitivity of polymer thin-film transistors based on poly(2methoxy-5-(2'-ethyl-hexyloxy)-1,4-phenylene vinylene) depends on the gate voltage. In the study made by Liu et al., when using the above-threshold mode, the on-state current increased slightly under illumination and the photosensitivity $\left(I_{\mathrm{ph}} / I_{\mathrm{dark}}\right)$ is 1.93 at an illumination intensity of 1200 lux and a gate voltage of $-25 \mathrm{~V}$. However, for the sub-threshold mode, the off-state current significantly increases with illumination intensity and the maximum photosensitivity $\left(I_{\mathrm{ph}} / I_{\mathrm{dark}}\right)$ is $198 \pm 17$ at the same illumination intensity and a gate voltage of $-5 \mathrm{~V}$ [54]. These results indicate that the photocurrent of an OTFT is modulated by the gate voltage.

The drain current in the linear region can be expressed by [55]

$I_{\mathrm{ds}}=\frac{W}{L} \mu C_{\mathrm{i}}\left[\left(V_{\mathrm{g}}-V_{\mathrm{th}}\right) V_{\mathrm{d}}-\frac{V_{\mathrm{d}}^{2}}{2}\right]$

where $I_{\mathrm{ds}}$ is the drain-source current, $W$ is the width of channel, $L$ is the channel length, $C_{\mathrm{i}}$ is the capacitance of the oxide layer, $V_{\mathrm{g}}$ is the gate voltage, $\mu$ is the mobility and $V_{\text {th }}$ is the threshold voltage. On the other hand, the drain current in the saturation region can be expressed by [56]

$I_{\mathrm{ds}}=\frac{W}{2 L} \mu C_{\mathrm{i}}\left(V_{\mathrm{G}}-V_{\mathrm{th}}\right)^{2}$

Fig. 5 shows the curve of $I_{\mathrm{ds}}^{1 / 2}-V_{\mathrm{g}}$ for the pentacene OTFT transistor. The field-effect mobility and threshold voltage of OTFT from $I_{\mathrm{ds}}^{1 / 2}-V_{\mathrm{g}}$ plot were found to be $0.021 \mathrm{~cm}^{2} /(\mathrm{V} \mathrm{s})$ and $28.88 \mathrm{~V}$, respectively. The results of the measured mobilities of the pentacene OTFT transistors studied in this work and in Refs. [57,58] suggest that the preparation process of the pentacene layer is very sensitive. Especially, the deposition rate has critical effects on the charge transport and the interface properties of the pentacene transistor.

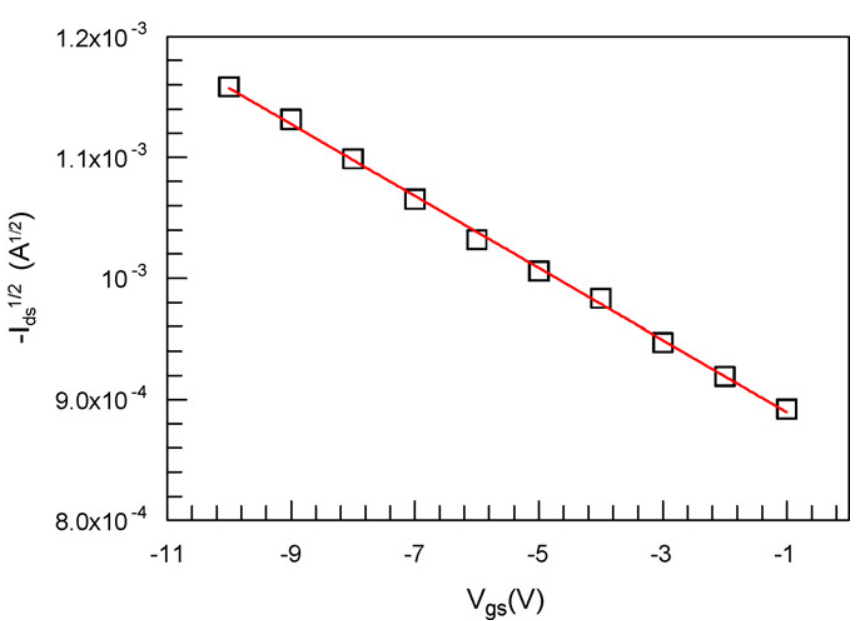

Fig. 5. Plot of $I_{\mathrm{ds}}^{1 / 2}-V_{\mathrm{g}}$ of the pentacene thin-film transistor.

\subsection{Interface state density properties of the pentacene thin-film transistor}

Since pentacene-OTFTs exhibit higher drain-source currents $\left(I_{\mathrm{ds}}\right)$ at negative applied gate voltages, our attention focused on the capacitance-voltage $(C-V)$ response at these voltages (Fig. 6). As the applied negative gate voltage is increased, the capacitance increases slightly and reaches a constant value. The oxide layer capacitance for the transistor was determined from the $C-V$ curve and was found to be $8.20 \mathrm{nF} / \mathrm{cm}^{2}$. This capacitance value obtained for a $250 \mathrm{~nm}$ thick $\mathrm{SiO}_{2}$ layer is in agreement with oxide layer capacitance values obtained by others for $\mathrm{SiO}_{2}$ layers $\left(6.91 \mathrm{nF} / \mathrm{cm}^{2}\right.$ for $500 \mathrm{~nm} \mathrm{SiO} 2$ layer and $11.5 \mathrm{nF} / \mathrm{cm}^{2}$ for $300 \mathrm{~nm} \mathrm{SiO}_{2}$ layer) [59,60].

The capacitance-frequency $(C-f)$ characteristics of the pentacene OTFT transistor have been measured in order to evaluate the presence of a continuous distribution of the interface states in the pentacene layer. Fig. 7 shows the measured capacitance as a function of the frequency of the transistor at 0.0 and $2 \mathrm{~V}$ bias voltages. The capacitance of the transistor increases with decreasing frequency and tends to be constant. At lower frequencies, the capacitance is resulting from interface states following the alternating current signal (AC). Whereas, at higher frequencies, the interface states in equilibrium with the semiconductor do not contribute to the capacitance, since the charge at the interface states cannot follow the applied AC signal.

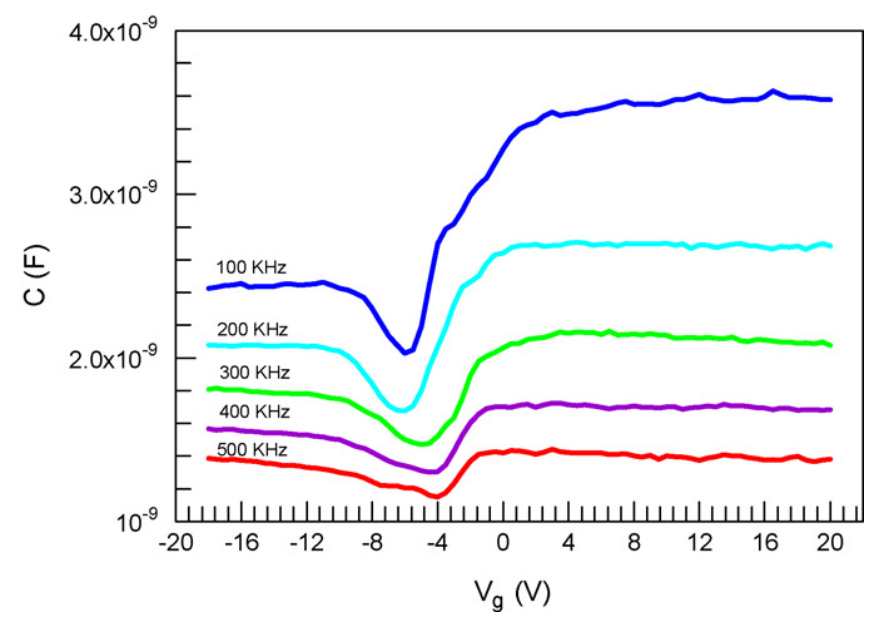

Fig. 6. The capacitance-voltage curves of the pentacene thin-film transistor at different frequencies. 


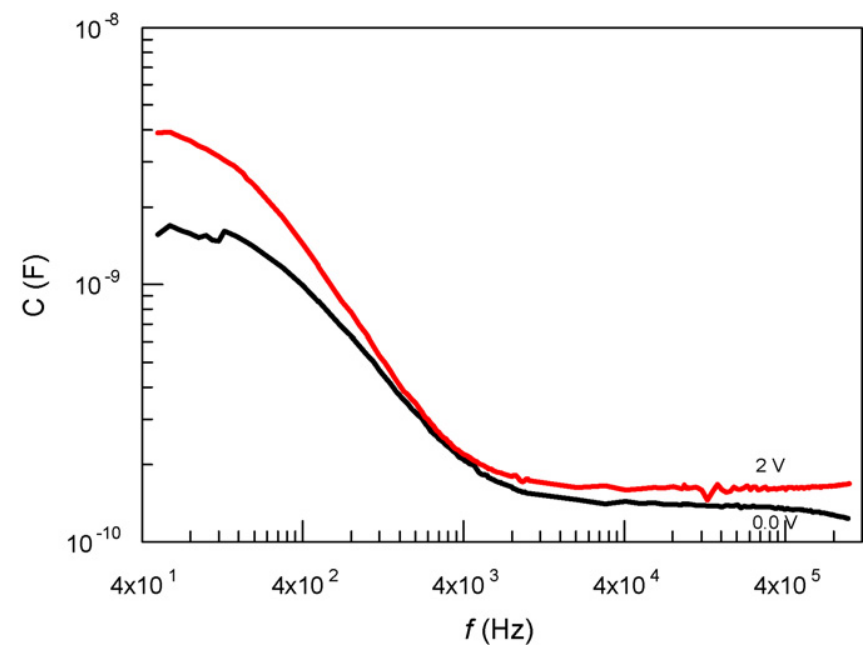

Fig. 7. The capacitance-frequency $(C-f)$ characteristics of the pentacene thin-film transistor at different voltages.

Admittance spectroscopy has been used for the interface trap analysis obtained from electrical properties of the metal-insulator-semiconductor devices. The complex admittance expression for the interface trap states can be defined as follows:

$Y=G_{p}+i \omega C_{p}$

where $G_{p}$ and $C_{p}$ are the real and imaginary parts of the admittance, respectively. The $G_{p}$ and $C_{p}$ relations is expressed by the following relation [61]:

$G_{p}=\frac{C_{\mathrm{it}}}{2 \tau} \ln \left(1+\omega^{2} \tau^{2}\right)$

$C_{p}=C_{d}+\frac{C_{\text {it }}}{\omega \tau} \arctan (\omega \tau)$

where $C_{\text {it }}=q A D_{\text {it }}, C_{\text {it }}$ and $D_{\text {it }}$ are the interface state capacitance and density, respectively, and $A$ is the diode contact area, $\omega$ is the angular frequency and $\tau$ is the time constant of the interface states. The parallel capacitance and conductance expressions in terms of the measured capacitance $C_{m}$ and conductance $G_{m}$ are defined as follows:

$C_{p}=\frac{-\left(G_{m} / \omega\right)^{2}\left(1 / C_{o X}\right)+C_{m}\left(1-\left(C_{m} / C_{o X}\right)\right)}{\left(G_{m} / \omega C_{o X}\right)^{2}+\left(1-\left(C_{m} / C_{o X}\right)\right)^{2}}$

and

$G_{p}=\frac{G_{m}}{\left(G_{m} / \omega C_{o x}\right)^{2}+\left(1-\left(C_{m} / C_{o x}\right)\right)^{2}}$, respectively.

If Eq. (4) is rearranged, the interface state conductance can be written as

$\frac{G_{p}}{\omega}=\frac{q A D_{i t} \tau}{2 \omega \tau} \ln \left(1+\omega^{2} \tau^{2}\right)$.

The maximum value of Eq. (4) is obtained by taking $\left|d\left(G_{p} / \omega\right) / d(\ln w)\right|=0$ where the maximum condition is found to be $\omega \tau=1.98$. This value is substituted into Eq. (4) and the interface state density is calculated by the following relation:

$D_{i t}=\frac{\left(G_{p} / \omega\right)_{\max }}{0.402 q A}$.

The plots of $(G / \omega)$ versus $\log f$ for the transistor are shown in Fig. 8. The peaks present in the plot can be explained as the existence of a continuous distribution of the interface states. As seen in Fig. 8, the peak position shifts to higher frequencies with $2 \mathrm{~V}$ bias voltage. This indicates a variation of the interface state density with an applied voltage. The interface state density for the

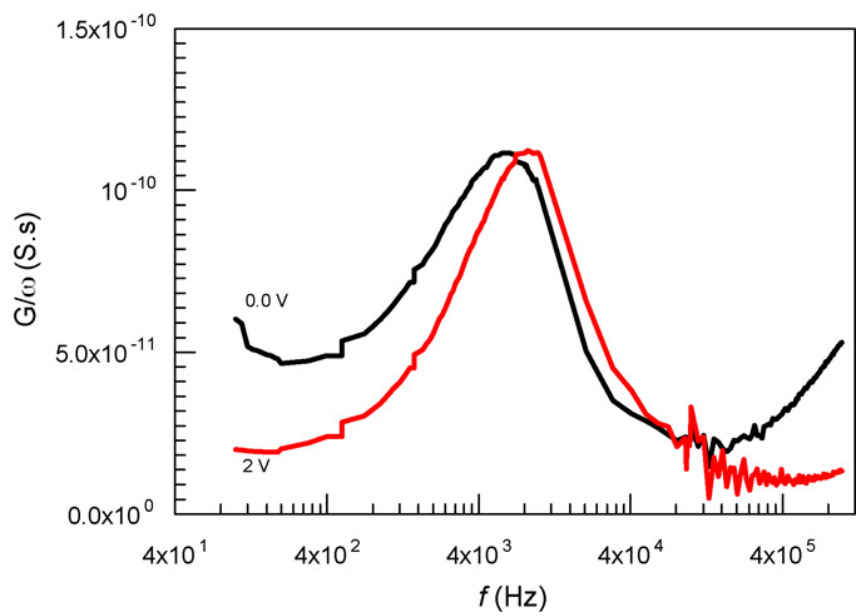

Fig. 8. Plots of $(G / \omega)$ versus $f$ of the pentacene thin-film transistor at different voltages.

transistor was determined from Fig. 8 and was found to be about $1.191 \times 10^{10} \mathrm{eV}^{-1} \mathrm{~cm}^{-2}$. The obtained $D_{\text {it }}$ value for the transistor studied is lower than that of organic field-effect transistors fabricated with pentacene as the active material and different polymeric dielectrics such as cyanoethylpullulan, poly(4-vinyl phenol), polymethylmethacrylate, parylene- $C$ and polyimide as the gate material [62]. The obtained $D_{\text {it }}$ value is a low value. This suggests that the interface states at this density are not effective on the device characteristics. Therefore, it is suggested that the interface states of organic thin-film transistors are effectively influenced by gate material.

\section{Conclusions}

The photovoltaic and interface state density properties of the pentacene thin-film transistor fabricated on an n-Si substrate with thermally oxidized $\mathrm{SiO}_{2}$ as a gate insulator have been investigated. The OTFT transistor showed p-channel characteristics and a photosensitivity $\left(I_{\mathrm{ph}} / I_{\mathrm{dark}}\right)$ of 1.45 at an illumination intensity of 3500 lux during the off state. The field-effect mobility and the interface state density of the pentacene OTFT were found to be $0.021 \mathrm{~cm}^{2} /(\mathrm{V} \mathrm{s})$ and $1.191 \times 10^{10} \mathrm{eV}^{-1} \mathrm{~cm}^{-2}$, respectively.

\section{Acknowledgment}

This study was financially supported with grants for major research projects, DPT 2003K 120390 by Turkish State Planning Organization (DPT). Dr. Ritchie Eanes is acknowledged for his technical and grammatical proof reading suggestions.

\section{References}

[1] J.H. Schon, S. Berg, Ch. Kloc, B. Batlogg, Ambipolar pentacene field-effect transistors and inverters science, 287 (2000) 1022.

[2] F. Garnier, G. Horowitz, D. Fichou, A. Yassar, Molecular order in organic-based field-effect transistors, Synth. Met. 81 (1996) 163.

[3] H. Klauk, D.J. Gundlach, T.N. Jackson, Fast organic thin-film transistor circuits, IEEE Electron. Device Lett. 20 (1999) 289.

[4] C.D. Dimitrakopoulos, B.K. Furman, T. Graham, S. Hedge, S. Purushothaman, Field effect transistors comprising molecular beam deposited $\alpha$ - $\omega$-di-hexylhexathienylene and polymeric insulators, Synth. Met. 92 (1998) 47.

[5] H. Klauk, K.J. Gundlach, M. Bonse, C.C. Kuo, T.N. Jackson, A reduced complexity process for organic thin film transistors, Appl. Phys. Lett. 76 (2000) 1692.

[6] A.R. Brown, A. Pomp, C.M. de Leeuw, Science 270 (1995) 972.

[7] A.R. Brown, C.P. Jarrett, D.M. de Leeuw, M. Matters, Synth. Met. 88 (1997) 37.

[8] M. Halik, H. Klauk, U. Zschieschang, T. Kriem, G. Schmid, W. Radlik, L. Wussow, Appl. Phys. Lett. 81 (2002) 289.

[9] G.H. Gelinck, T.C.T. Genus, D.M. de Leeuw, High-performance all-polymer integrated circuits, Appl. Phys. Lett. 77 (2000) 1487. 
[10] C.J. Drury, C.M.J. Mutsaers, C.M. Hart, M. Matters, D.M. de Leeuw, Low-cost allpolymer integrated circuits, Appl. Phys. Lett. 73 (1998) 108.

[11] D. Voss, Cheap and cheerful circuits, Nature 407 (2000) 442.

[12] C.D. Sheraw, L. Zhou, J.R. Huang, D.J. Gundlach, T.N. Jackson, M.G. Kane, I.G. Hill, M.S. Hammond, J. Campi, B.K. Greening, J. Francl, J. West, Organic thin-film transistor-driven polymer-dispersed liquid crystal displays on flexible polymeric substrates, Appl. Phys. Lett. 80 (2002) 1088.

[13] A.R. Brown, A. Pomp, C.M. Hart, D.M. de Leeuw, Logic gates made from polymer transistors and their use in ring oscillators, Science 270 (1995) 972.

[14] F.-J.M.Z. Heringdorf, M.C. Reuter, R.M. Tromp, Growth dynamics of pentacene thin films, Nature 412 (2001) 517.

[15] C. Bartic, G. Borghs, Organic thin-film transistors as transducers for (bio) analytical applications, Anal. Bioanal. Chem. 384 (2) (2006) 354.

[16] P.F. Baude, D.A. Ender, M.A. Hasse, T.W. Kelley, D.V. Muyres, S.D. Thesis, Pentacene-based radio-frequency identification circuitry, Appl. Phys. Lett. 82 (22) (2003) 3964

[17] P.R.L. Malenfant, C.D. Dimitrakopoulos, J.D. Gelorme, L.L. Kosbar, T.O. Graham, A. Curioni, W. Andreoni, N-type organic thin-film transistor with high field-effect mobility based on a N,N'-dialkyl-3,4,9,10-perylene tetracarboxylic diimide derivative, Appl. Phys. Lett. 80 (14) (2002) 2517.

[18] H.E. Katz, J. Johnson, A.J. Lovinger, W. Li, Naphthalenetetracarboxylic diimide-based n-channel transistor semiconductors: structural variation and thiol-enhanced gold contacts, J. Am. Chem. Soc. 122 (32) (2000) 7787.

[19] J. Zhang, J. Wang, H. Wang, D. Yan, Organic thin-film transistors in sandwich configuration, Appl. Phys. Lett. 84 (2004) 142.

[20] J. Yuan, J. Zhang, J. Wang, X. Yan, C. Yan, Bottom-contact organic field-effect transistors having low-dielectric layer under source and drain electrodes, Appl. Phys. Lett. 82 (2003) 3967.

[21] Z. Bao, A.J. Lovinger, A. Dodabalapur, Organic field-effect transistors with high mobility based on copper phthalocyanine, Appl. Phys. Lett. 69 (1996) 3066.

[22] Z. Bao, A.J. Lovinger, J. Brown, New air-stable n-channel thin film transistors, J Am. Chem. Soc. 20 (1998) 207.

[23] T.W. Kelley, D.V. Muyres, P.F. Baude, T.P. Smith, T.D. Jones, High performance organic thin film transistors, Mater. Res. Soc. Symp. Proc. 771 (2003) 169-175.

[24] Y. Lin, D.J. Gundlach, S.F. Nelson, T.N. Jackson, Pentacene-based organic thin-film transistors, IEEE Trans. Electron. Dev. 44 (1997) 1325

[25] H. Klauk, M. Halik, U. Zschieschang, G. Schmid, W. Radlik, High-mobility polymer gate dielectric pentacene thin film transistors, J. Appl. Phys. 92 (2002) 5259.

[26] Y. Jang, D.H. Kim, Y.D. Park, J.H. Cho, M. Hwang, K. Cho, Low-voltage and highfield-effect mobility organic transistors with a polymer insulator, Appl. Phys. Lett. 88 (2006) 072101.

[27] S.F. Nelson, Y.-Y. Lin, D.J. Gundlach, T.N. Jackson, Temperature-independent transport in high-mobility pentacene transistors, Appl. Phys. Lett. 72 (1998) 1854.

[28] M. Shtein, J. Mapel, J.B. Benziger, S.R. Forrest, Effects of film morphology and gate dielectric surface preparation on the electrical characteristics of organic-vaporphase-deposited pentacene thin-film transistors, Appl. Phys. Lett. 81 (2002) 268.

[29] M. Halik, H. Klauk, U. Zschieschang, G. Schmid, C. Dehm, M. Schutz, S. Maisch, F. Effenberger, M. Brunnbauer, F. Stellacci, Low-voltage organic transistors with an amorphous molecular gate dielectric, Nature (London) 431 (2004) 963.

[30] C.D. Dimitrakopoulos, P.R.L. Malenfant, Organic thin film transistors for large area electronics, Adv. Mater. (Weinheim, Germany) 14 (2002) 99.

[31] D.J. Gundlach, Y.Y. Lin, T.N. Jackson, S.F. Nelson, D.G. Schlom, Pentacene organic thin film transistors-molecular ordering and mobility, IEEE Electron. Device Lett. 18 (1997) 87

[32] C. Dimitrakopoulos, S. Purushothaman, J. Kymissis, A. Callegari, J. Shaw, Lowvoltage organic transistors on plastic comprising high-dielectric constant gate insulators, Science 283 (1999) 822.

[33] J.H. Kang, Demetrio da Silva Filho, Jean-Luc Bredas, X.-Y. Zhua, Shallow trap states in pentacene thin films from molecular sliding, Appl. Phys. Lett. 86(2005) 152115.

[34] C.C. Mattheus, A.B. Dros, J. Baas, A. Meetsma, J.L. de Boer, T.T.M. Palstra, Polymorphism in pentacene, Acta Crystallogr. Sect. C: Cryst. Struct. Commun. C57 (2001) 939.

[35] T. Minakata, H. Imai, M. Ozaki, K. Saco, Structural studies on highly ordered and highly conductive thin films of pentacene, J. Appl. Phys. 72 (1992) 5220.

[36] P.V. Pesavento, R.J. Chesterfield, C.R. Newman, C.D. Frisbie, Gated four-probe measurements on pentacene thin-film transistors: contact resistance as a function of gate voltage and temperature, J. Appl. Phys. 96 (2004) 7312.

[37] M. Nakamura, N. Goto, N. Ohashi, M. Sakai, K. Kudo, Potential mapping of pentacene thin-film transistors using purely electric atomic-force-microscope potentiometry, Appl. Phys. Lett. 86 (2005) 122112.

[38] L. Bürgi, H. Sirringhaus, R.H. Friend, Noncontact potentiometry of polymer fieldeffect transistors, Appl. Phys. Lett. 80 (2002) 2913.

[39] J.A. Nichols, D.J. Gundlach, T.N. Jackson, Potential imaging of pentacene organic thin-film transistors, Appl. Phys. Lett. 83 (2003) 2366.

[40] D.V. Lang, X. Chi, T. Siegrist, A.M. Sergent, A.P. Ramirez, Amorphouslike density of gap states in single-crystal pentacene, Phys. Rev. Lett. 93 (2004) 086802

[41] E.K. Muller, J.A. Marohn, Microscopic evidence for spatially inhomogeneous charge trapping in pentacene, Adv. Mater. 17 (2005) 1410.
[42] M. Kiguchi, M. Nakayama, T. Shimada, K. Saiki, Electric induced charge injection and exhaustion in organic thin film transistors, Phys. Rev. B 71 (2005) 035332.

[43] D.H. Kim, Y.D. Park, Y. Jang, H. Yang, Y.H. Kim, J.I. Han, D.G. Moon, S. Park, T. Chang, C. Chang, M. Joo, C.Y. Ryu, K. Cho, Enhancement of field-effect mobility due to surface-mediated molecular ordering in regioregular polythiophene thin film transistors, Adv. Funct. Mater. 15 (2005) 77.

[44] M. Yoshida, S. Uemura, T. Kodzasa, T. Kamata, M. Matsuzawa, T. Kawai, Surface potential control of an insulator layer for the high performance organic FET, Synth. Met. 137 (2003) 967

[45] Y.Y. Noh, D.Y. Kim, K. Yase, Highly sensitive thin-film organic phototransistors effect of wavelength of light source on device performance, JAP 98 (7) (2005) 074505.

[46] M. Debucquoy, S. Verlaak, S. Steudel, K. Myny, J. Genoe, P. Heremans, Correlation between bias stress instability and phototransistor operation of pentacene thinfilm transistors, Appl. Phys. Lett. 91 (2007) 103508.

[47] A.J. Seeds, A.A.A. Salles, Optical control of microwave semiconductor devices, IEEE Trans. Microwave Theory Tech. 38 (1990) 577.

[48] A. Madjar, P.R. Herczfeld, A. Paolella, Analytical model for optically generated currents in GaAs MESFETs, IEEE Trans. Microwave Theory Tech. 40 (1992) 1681.

[49] M.A. Romeo, M.A.G. Martinez, P.R. Herczfeld, An analytical model for the photodetection mechanisms in high-electron mobility transistors, IEEE Trans. Microwave Theory Tech. 44 (1996) 2279.

[50] B. Lucas, A. El Amrani, A. Moliton, Mol. Cryst. Liq. Cryst. 485 (2008) 955

[51] Y.Y. Noh, D.Y. Kim, Organic phototransistor based on pentacene as an efficient red light sensor, Solid-State Electron. 51 (77) (2007) 1052.

[52] F.J.M.Z. Heringdorf, M.C. Reuter, R.M. Tromp, Growth dynamics of pentacene thin films, Nature (London) 412 (2001) 517.

[53] M. Shtein, J. Mapel, J.B. Benzinger, S.R. Forrest, Effects of film morphology and gate dielectric surface preparation on the electrical characteristics of organicvapor-phase-deposited pentacene thin-film transistors, Appl. Phys. Lett. 81 (2002) 268.

[54] Y.R. Liu, J.B. Peng, P.T. Lai, Photo-response of polymer thin-film transistors based on poly(2-methoxy-5-(2'-ethyl-hexyloxy)-1,4-phenylene vinylene), Thin Solid Films 516 (2008) 4295

[55] R.F. Pierret, Semiconductor Device Fundamentals, Addison-Wesley Publishing Company, 1996.

[56] S.M. Sze, Physics of Semiconductor Devices, second ed., John Wiley \& Sons, 1981.

[57] J.X. Tang, C.S. Lee, M.Y. Chan, S.T. Lee, Enhanced electrical properties of pentacene-based organic thin-film transistors by modifying the gate insulator surface, Appl. Surf. Sci. 254/23 (2008) 7688.

[58] Jae Hoon Park, Chang Heon Kang, Yeon Ju Kim, Yong Soo Lee, Jong Sun Choi, Characteristics of pentacene-based thin-film transistors, Mater. Sci. Eng. C 24 (2004) 27.

[59] Y. Hosoi, D. Tsunami, H. Ishii, Y. Furukaw, Chem. Phys. Lett. 436 (2007) 139.

[60] F.A. Yildirim, R.R. Schliewe, W. Bauhofer, R.M. Meixner, H. Goebel, W. Krautschneider, Gate insulators and interface effects in organic thin-film transistors, Org. Electron. 9 (2008) 70.

[61] E.H. Nicollian, J.R. Brews, MOS (Metal Oxide Semiconductor) Physics and Technology, Wiley, New York, 1982.

[62] K.N. Narayanan Unni, S. Dabos-Seignon, A.K. Pandey, J.-M. Nunzi, Influence of the polymer dielectric characteristics on the performance of pentacene organic field-effect transistors, Solid-State Electron. 52 (2008) 179

\section{Biographies}

Salih Okur received his bachelor's degree in Physics Education from Hacettepe University in Ankara, Turkey in 1989, his master's degree in Physics from Ankara University in Ankara, Turkey in 1992, a master's degree in Physics from Illinois Institute of Technology in Chicago, Illinois, USA in 1996, and his Ph.D. in Physics from Illinois Institute of Technology in Chicago, Illinois, USA in 1998. He is currently an Associate Professor in the Department of Physics at Izmir Institute of Technology in Izmir, Turkey. His current research interests include organic thin films, SAM-LB films, thin-film interfaces, and their application to electronic devices such as organic photovoltaics, OLEDs, OTFTs, nano-wires and sensors.

Fahrettin Yakuphanoglu obtained his master's degree from Solid State Physics, Firat University, Elazığ, Turkey, 1996-1998, Ph.D. from Solid State Physics, Firat University, Elazığ, Turkey, 1998-2002. He was Assoc. Prof. in Solid State Physics, Firat University, Elazı̆̆, Turkey, 2004. His main achievements are-(A) organic semiconductors (polymers, monomers, organic compounds): (i) electrical, dielectrical, thermal and optical properties; (ii) electronic devices applications of organic semiconductors such as Schottky diode, $\mathrm{P}-\mathrm{N}$ heterojunction diode, metal-insulator-semiconductor junctions, solar cells, thin-film transistor, photodiode, optical sensor. (B) Optical materials: (i) determination of the optical constants, (ii) refractive index dispersion. (C) Liquid crystals and electro-optical properties. (D) Nanostructure semiconductor materials and their electronic devices applications. 